ORNL/TM-1999/129

\title{
Application of Phosphor Thermometry to a Galvanneal Temperature Measurement System
}

David L. Beshears, S. W. Allison, William H. Andrews, Michael R. Cates, Eric B. Grann, Wayne W. Manges, Timothy J. McIntyre, Matthew B. Scudiere, Marc L. Simpson, Robert M. Childs Oak Ridge National Laboratory Oak Ridge, Tennessee 37831-8058 USA

\author{
Joe Vehec \\ Advanced Process Control
}

The American Iron and Steel Institute Pittsburgh, Pennsylvania 15222 USA

\author{
Liwei Zhang \\ Technical Center \\ National Steel Corp \\ Trenton, Michigan 48183-2147 USA
}




DISCLAIMER
This report was prepared as an account of work sponsored by an agency of
the United States Government. Neither the United States government nor
any agency thereof, or any of their employees, makes any warranty,
expressed or implied, or assumes any legal liability or responsibility for
any third party's use, or the results of such use, of any information,
apparatus, product or process disclosed in this report, or represents that
its use by such third party would not infringe privately owned rights.
Reference herein to any specific commercial product, process, or service
by trade name, trademark, manufacturer, or otherwise, does not
necessarily constitute or imply its endorsement, recommendation, or
favoring by the United States Government or any agency thereof. The
views and opinions of authors expressed herein do not necessarily state or
reflect those of the United States Government or any agency thereof.


ORNL/TM-1999/129

\title{
Application of Phosphor Thermometry to a Galvanneal Temperature Measurement System
}

David L. Beshears, S. W. Allison, William H. Andrews, Michael R. Cates,

Eric B. Grann, Wayne W. Manges, Timothy J. McIntyre, Matthew B. Scudiere,

Marc L. Simpson, Robert M. Childs

Oak Ridge National Laboratory

Oak Ridge, Tennessee 37831-8058

\author{
Joe Vehec \\ Advanced Process Control \\ The American Iron and Steel Institute \\ Pittsburgh, Pennsylvania 15222
}

\author{
Liwei Zhang \\ Technical Center \\ National Steel Corp \\ Trenton, Michigan 48183-2147
}

June 1999

\author{
Prepared by the \\ Oak Ridge National Laboratory, \\ Oak Ridge, Tennessee, 37831-6285 \\ managed by \\ LOCKHEED MARTIN ENERGY RESEARCH CORPORATION, \\ for the \\ U. S. DEPARTMENT OF ENERGY \\ under contract No. DE-AC05-96OR22464.
}




\section{Table of Contents}

Abstract
Introduction
Technical Approach
Field Testing




\section{List of Figures}

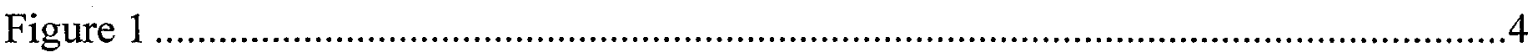

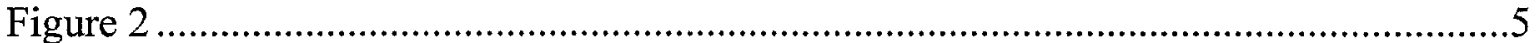

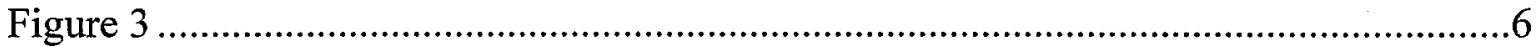

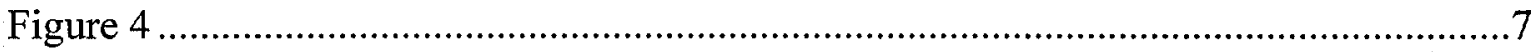

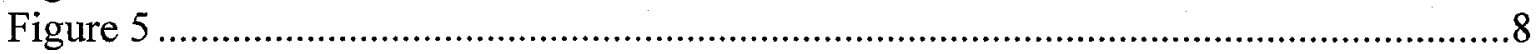

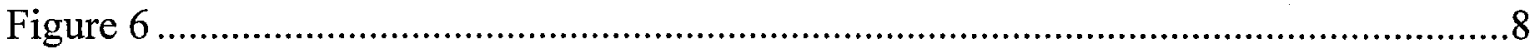

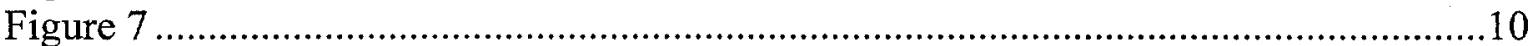

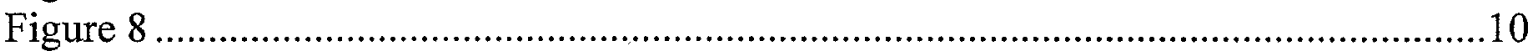

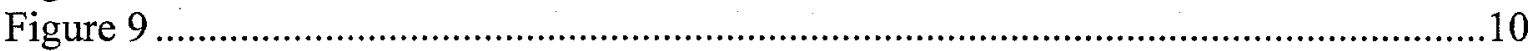

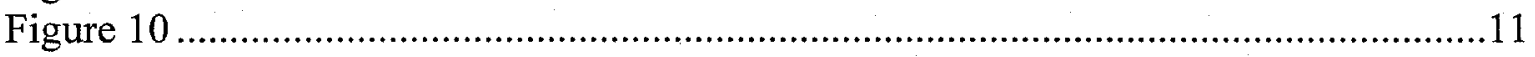

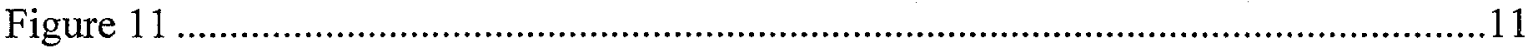

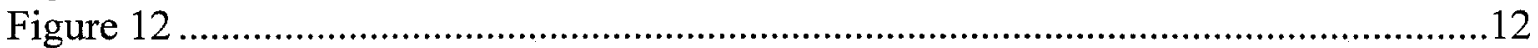

\section{List of Tables}

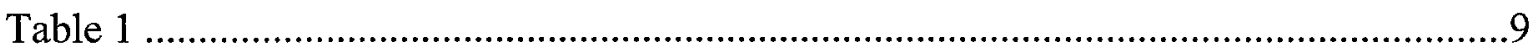




\begin{abstract}
The Galvanneal Temperature Measurement System (GTMS) was developed for the American Iron and Steel Institute by the Oak Ridge National Laboratory through a partnership with the National Steel Midwest Division in Portage, Indiana. The GTMS provides crucial on-line thermal process control information during the manufacturing of galvanneal steel. The system has been used with the induction furnaces to measure temperatures ranging from 840 to $1292^{\circ} \mathrm{F}$ with an accuracy of better than $+/-9^{\circ} \mathrm{F}$. The GTMS provides accurate, reliable temperature information thus ensuring a high quality product, reducing waste, and saving energy. The production of uniform, high-quality galvanneal steel is only possible through strict temperature control.
\end{abstract}




\section{INTRODUCTION}

This report describes a device that was developed and demonstrated for in-process measurement and control of galvanneal steel strip temperatures. Reliable temperature measurements will enable more complete galvanneal process characterization and a derivation of a dynamic model for the control of the process. Hot dip galvannealed steel has been extensively used in automotive industry because of its weldability, paintability, and cosmetic corrosion resistance. Galvanneal steel provides a superior product to pure zinc galvanized steel. Surface temperature changes, which result from process variations in the galvannealing stage of processing, directly affect the quality of the steel and therefore, the competitiveness of the U.S. steel industry in a worldwide market. Currently, no accurate in-process measurement of galvanneal steel surface temperature is available. Several parameters will vary during production, such as sheet thickness, sheet speed (which is up to $350 \mathrm{ft} / \mathrm{min}$ ), and power to the induction furnaces. All these parameters affect the steel surface temperature and must be controlled to achieve a high quality end product. The projected benefits of the technology are enhanced product quality, less product variability, and reduced process spoilage.

The project was funded jointly by the American Iron and Steel Institute (AISI) and the Department of Energy's (DOE) Office of Industrial Technology (OIT). The galvanneal temperature measurement system described here was first demonstrated at National Steel's Midwest plant in Portage, Indiana, in 1997. A second system was installed in Bethlehem Steel's Burns Harbor facility, Burns Harbor, Indiana, on the phosphate/ chromatic coating line in May of 1998.

\section{TECHNICAL APPROACH}

Thermographic phosphors are relatively inert, ceramic materials activated with a rare earth material (typically less than 1\%) which emit light with a distinctive spectral distribution when suitably excited by an energy source such as an electron beam, x-ray source, or ultraviolet light. If the source is pulsed, then the fluorescence emitted will persist for a characteristic duration that is temperature dependent. Different spectral components from the same material may even exhibit different temperature responses. These changes are independent of the emissivity of the surface to which the fluorescing material is attached. A review of noncontact phosphor thermometry, which includes nearly three hundred references, can be found in "Remote Thermometry with Thermographic Phosphors: Instrumentation and Applications" (Allison and Gillies, 1997).

The brightness of phosphor fluorescence decreases exponentially in time, and the time required to decrease by $1 / \mathrm{e}$ is termed the decay time or lifetime. This is illustrated in Figure 1 for a representative phosphor where the decrease is seen to be more rapid at the 
higher temperature. Provided the decay is described by a single exponential and there are no chemical reactions altering the phosphor, the decay time is a single-valued function of temperature over a wide and useful range. The decay time based approach was chosen for this application, although there are other fluorescence properties that may be exploited to ascertain temperature (e.g., emission intensity). Decay rate measurements tend to retain calibration better than intensity-based approaches (Wickersheim, 1992; Sun, 1992; Grattan and Zhang, 1995).

ORNL-DWG 97-1687 EFG

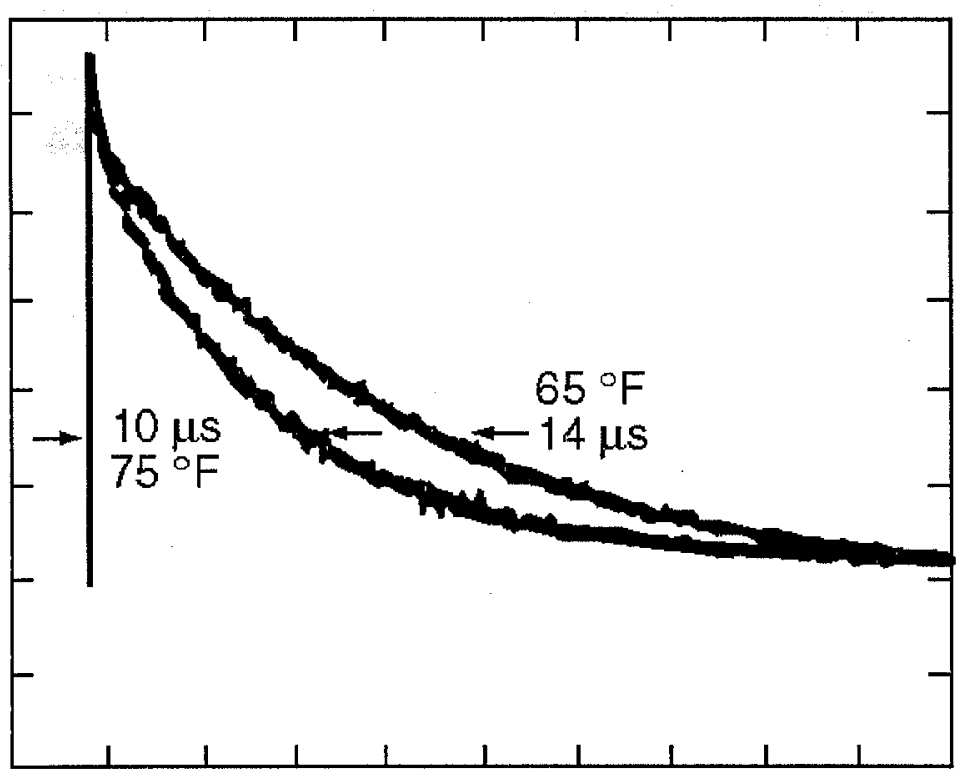

Figure 1 - Time decay for $\mathrm{La} 2 \mathrm{O} 2: \mathrm{EU}$ at 65 and $75^{\circ} \mathrm{F}$

A collaboration of Department of Energy laboratories, (ORNL, Los Alamos National Laboratory (LANL), and EG\&G Energy Measurements - now Bechtel Nevada Special Technologies Laboratory) has utilized and developed the technique for a wide variety of low, ambient, and high temperature applications as reported in recent years (Noel, Turley, and Allison, 1994). Surfaces of motors, centrifuges, and turbines, for example, have been diagnosed by this method (Noel, Turley, and Allison, 1994; Cates, Allison, Marshall, Franks, Davis, Nelson, and Noel, 1984; Allison, Gillies, Cates, and Noel, 1988). In addition to the advantage that the technique is independent of emissivity, the measurement can be made from a distance.

Infrared pyrometry is sometimes used as a temperature indicator for galvanneal processing. Unfortunately, the accuracy of pyrometry depends on knowing the emissivity of a surface. Because, the emissivity of the molten layer of zinc on the sheet is quite low (reflective) and varies rapidly during the process, pyrometry is subject to corresponding uncertainty and unreliability. 
Figure 2 illustrates how the GTMS is configured for galvanneal thermometry. A deposition apparatus delivers a small amount of phosphor to the surface of the steel sheet immediately after it emerges from the zinc bath. When the phosphor spot moves up into the field-of-view of the collection optics (called the optics head), a laser fires a pulse of light into a large core (1-mm) optical fiber. The light is delivered to the phosphor spot on the galvanneal surface and a lens system is used to focus the light onto the surface of interest. The phosphor absorbs the ultraviolet light and emits some of the absorbed energy as visible fluorescence. The duration, also called the decay time, is temperature

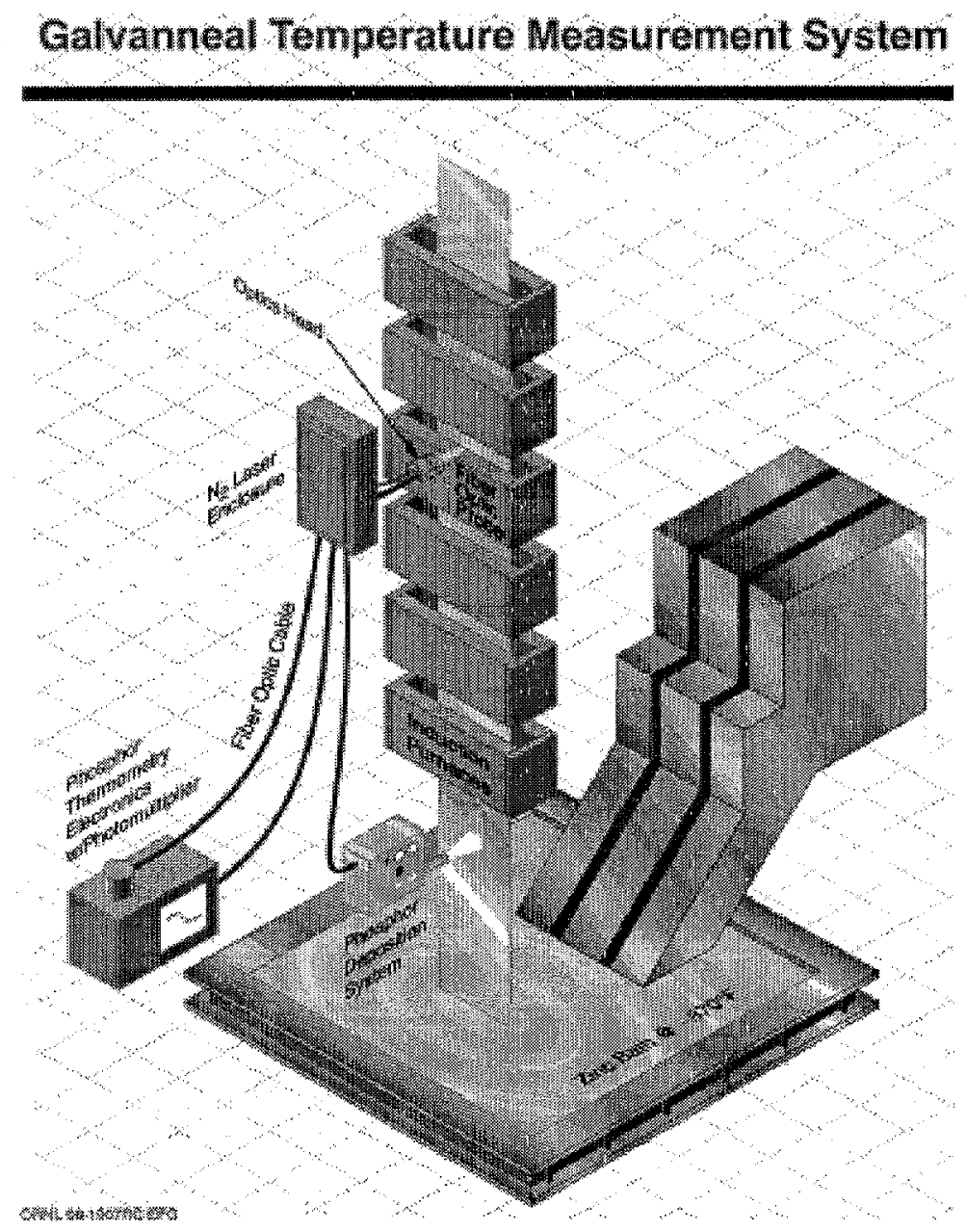

Figure 2 - Phosphor thermometry schematic

dependent. The lens system collects the fluorescence and images it onto a fiberoptic cable. The light is conveyed to a spectral band-pass filter, which transmits only the desired temperature-dependent color to the photomultiplier tube detector. A data acquisition system converts the detector signal to temperature. The data acquisition 
computer also produces control signals for triggering the deposition system and the laser. Photographs of the actual hardware installed on the phosphate/chromate coating section of the galvanneal line are shown in Figure 3.

\section{Galvanneal Temperature Measurement System Installed at Bethlehem Steel on the Phosphate/Chromate Coating Line}
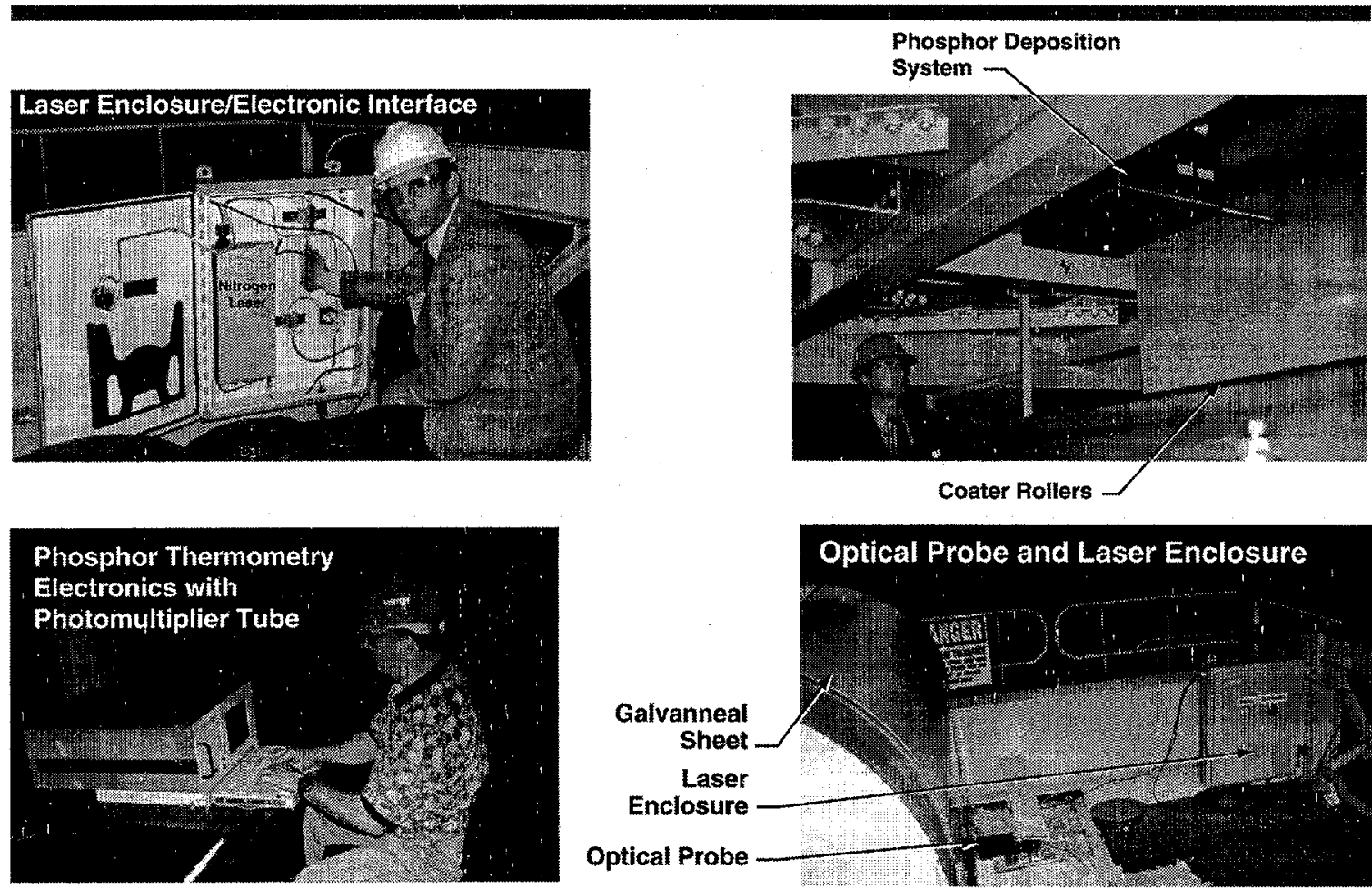

OANL $999290 \mathrm{EFC}$

Figure 3 - Photographs of the GTMS installed at Bethlehem Steel

The advantages of high temperature measurements that incorporate thermographic phosphor techniques are many. Since the method can be performed remotely, it is useful in hazardous, noisy, and explosive environments. Optical temperature measurements of this kind are also immune to electrical interference and have a wide sensing range based on the selection of the proper phosphor. With current state-of-the-art electronic equipment, measurements can be made at a rate of 5000 per second, if desired, for process monitoring and control. Figure 4 illustrates both what was demonstrated as part of the AISI's goals and the capabilities of phosphor thermometry as demonstrated in other field and laboratory test programs. 
This successful collaboration with the AISI continues to provide important benefits to the ORNL, the steel industry, and the nation. There are numerous potential extensions of the technology:

Steel

- Slab heating

- Melt temperature

- Roller temperature

Other Materials

- Galvalume

- Ceramic

- Aluminum

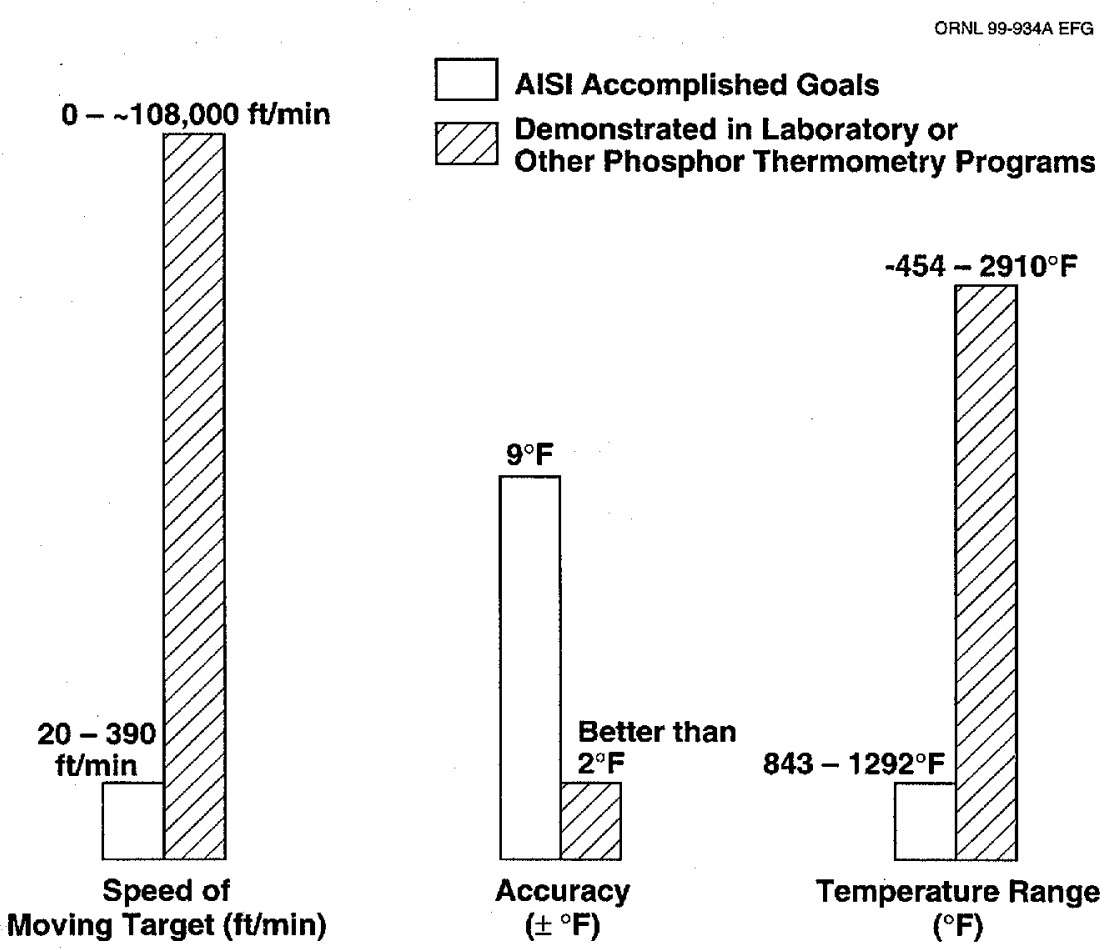

Other Industries

- Aircraft components

- Petroleum

- Pulp and paper

- Glass

Figure 4-Capability of phosphor thermometry technology

SYSTEM DEVELOPMENT

A variety of phosphor materials was selected and tested for the specified induction furnace galvanneal temperature range of 450 to $650^{\circ} \mathrm{C}\left(800\right.$ to $\left.1200^{\circ} \mathrm{F}\right)$ and the phosphate/chromate galvanneal coating line range of 24 to $100^{\circ} \mathrm{C}\left(75\right.$ to $\left.212^{\circ} \mathrm{F}\right)$. At the 
completion of the phosphor materials evaluation, two phosphor materials were chosen: phosphor $\mathrm{A}$ for the high temperature range, and phosphor $\mathrm{B}$ for the low temperature range. Careful determinations of decay time versus temperature were performed in the lab to obtain calibration curves for each phosphor. The calibration curve for the high temperature phosphor $\mathrm{A}$ is depicted in Figure 5. The calibration curve for phosphor $\mathrm{B}$ is depicted in Figure 6.

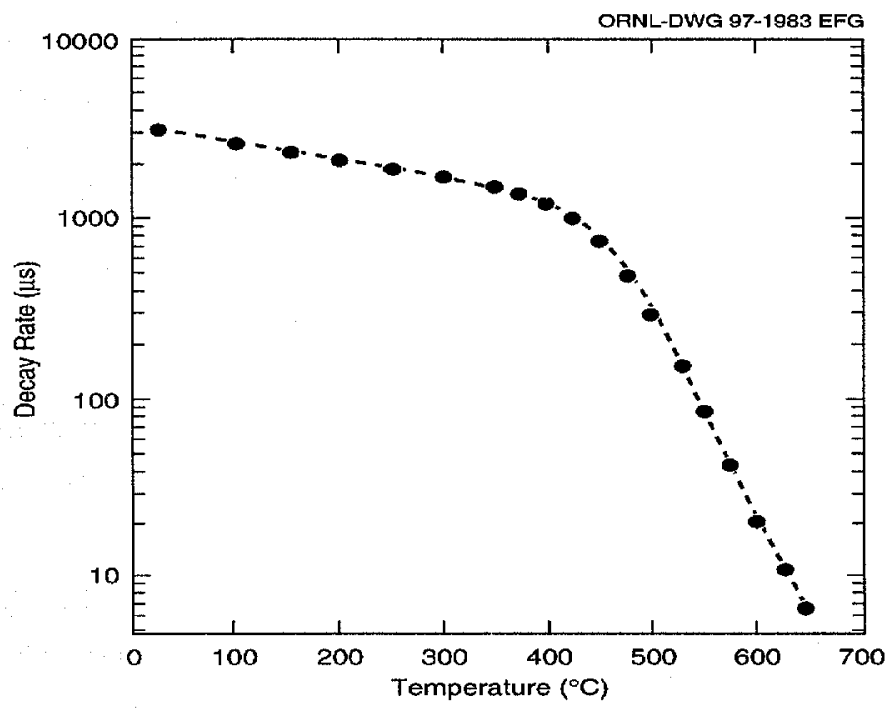

Figure 5 - Calibration for phosphor A

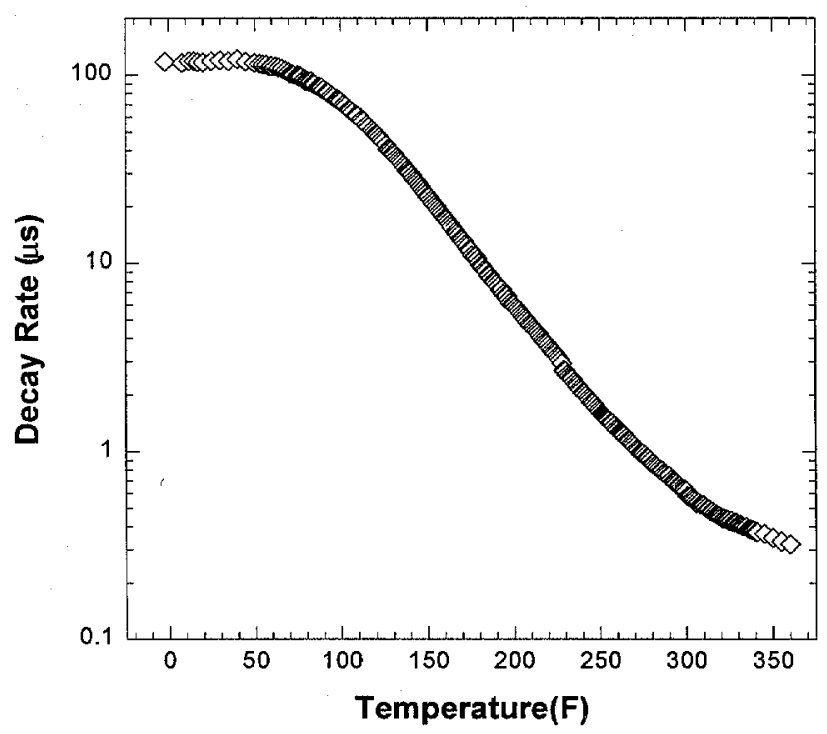

Figure 6-Calibration for low temperature phosphor B 
A variety of light sources may be used to excite fluorescence for either of these two phosphors. A portable nitrogen laser, which emits at $337 \mathrm{~nm}$ was chosen for its size, cost, and laser safety considerations. The output ranges from the nitrogen laser is approximately 0.1 to $0.3 \mathrm{~mJ}$ at a repetition rate of 1 to $30 \mathrm{~Hz}$.

Thermal modeling established that a thin phosphor layer will rapidly equilibrate with the galvanneal surface temperature. Calculations determined the time required for the phosphor to come to temperature once deposited on the galvanneal strip. Published values were used for the thermal conductivity, density, and specific heat for one of the phosphors chosen and it was assumed that these values are comparable for the second phosphor. Table 1 depicts the results.

TABLE I - Thermal modeling results

\begin{tabular}{|c|c|c|c|c|}
\hline $\begin{array}{c}\text { Phosphor } \\
\text { thickness } \\
\qquad(\mu \mathrm{m})\end{array}$ & $\begin{array}{c}\text { Initial } \\
\text { Temperature } \\
\left({ }^{\circ} \mathrm{F}\right)\end{array}$ & $\begin{array}{c}\text { Steel } \\
\text { Temperature } \\
\left({ }^{\circ} \mathrm{F}\right)\end{array}$ & $\begin{array}{l}\text { Time to } \\
\text { get within } \\
9^{\circ} \mathrm{F}(\mathrm{ms})\end{array}$ & $\begin{array}{l}\text { Time to } \\
\text { get within } \\
4^{\circ} \mathrm{F}(\mathrm{ms})\end{array}$ \\
\hline 250 & 86 & 1112 & 11 & 25 \\
\hline 50 & 86 & 1112 & 0.6 & 0.75 \\
\hline
\end{tabular}

\section{FIELD TESTING}

A number of on line tests were performed at National Steel's Midwest Division in Portage, Indiana, and Bethlehem Steel's Burns Harbor facility in Burns Harbor, Indiana. The electronics and optics for the final embodiment evolved during the course of the development. One of our early tests involved an approach where the detector was located within a few feet of the induction heaters. This led to a large amount of radio frequency interference (RFI) superimposed on the fluorescence signal as shown in Figure 7. Although decay time and, therefore, temperature can be determined from such data with sufficient analytical and computational effort, we completely eliminated the RFI by moving the light source and detector some distance away from the measurement zone and by accessing the zone via fiber optics. This is shown in Figure 8 . The sharp spike at the beginning of the decay curve is due, in this case, to some leakage of laser light $(<1 \mu \mathrm{s})$ to the detector. The decay time algorithm ignores this part of the decay curve in determining the lifetime of the fluorescence. The final optics head design is shown in the photo of Figure 9. 

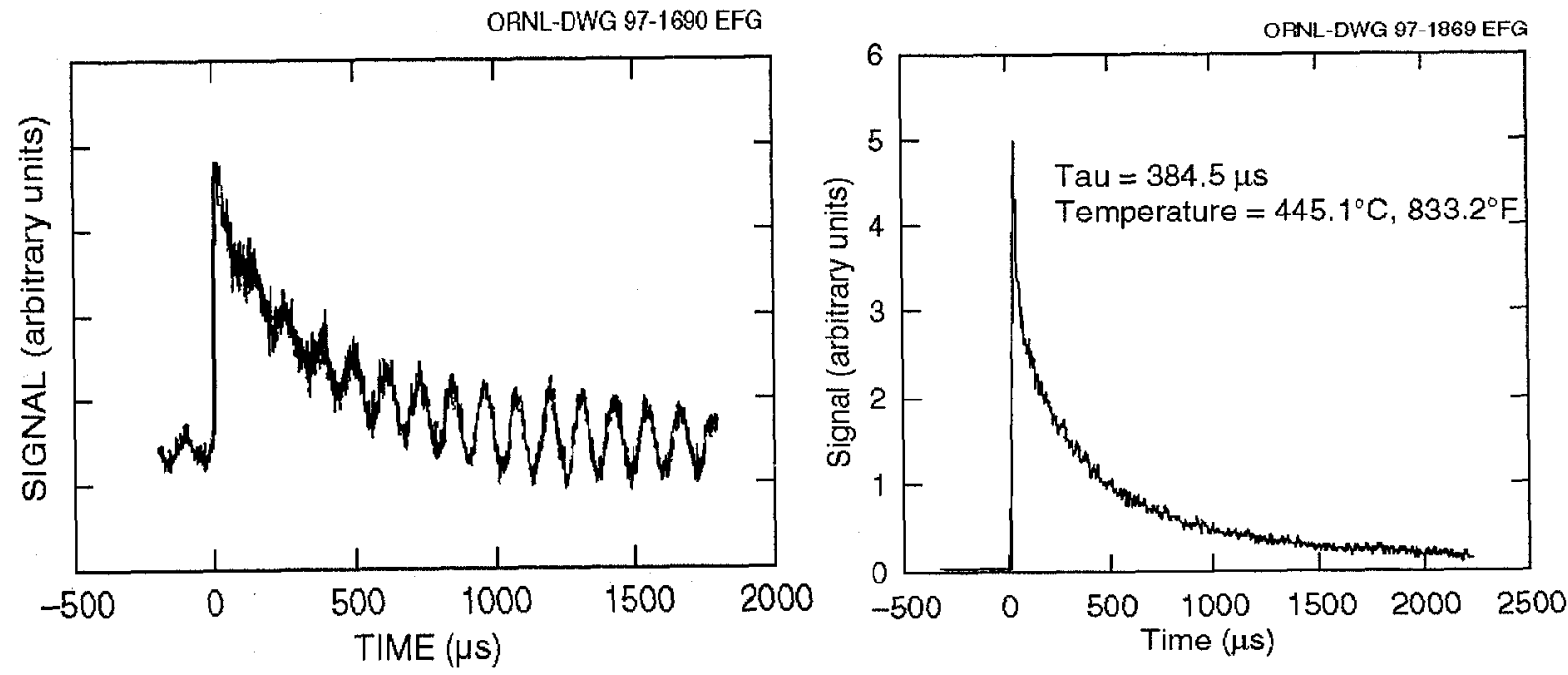

Figure 7 - Fluorescence signal with RFI

Figure 8 - Signal with fiberoptics

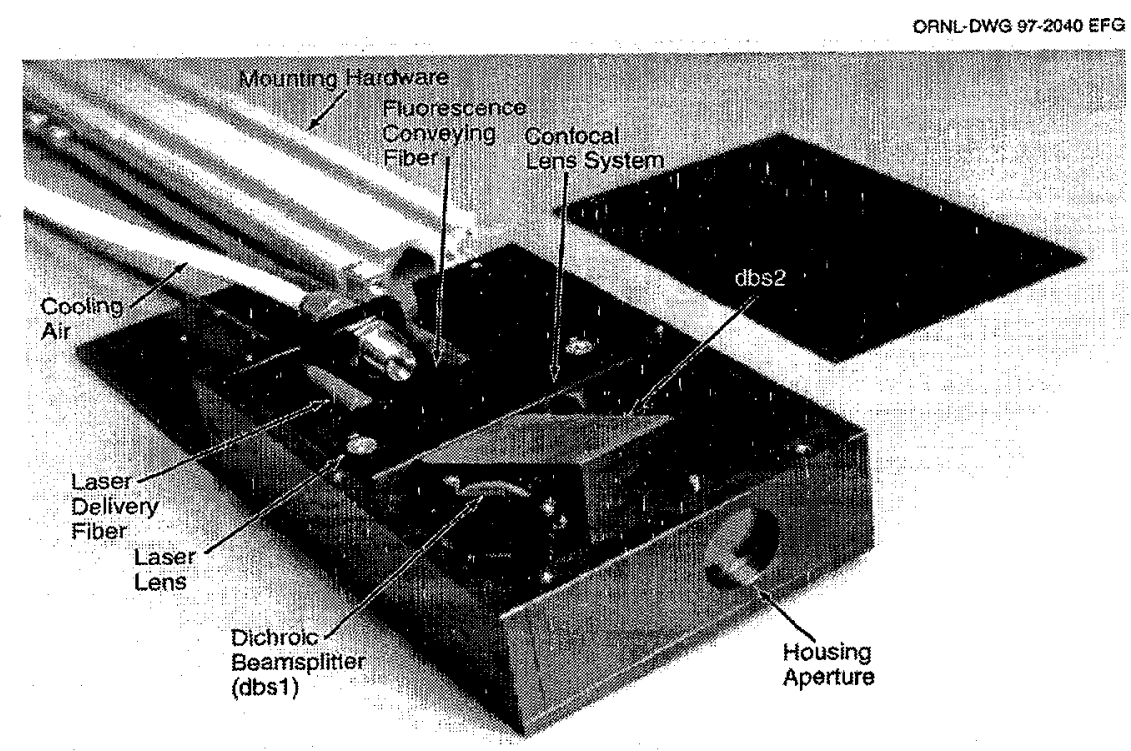

Figure 9 - Optical head

Figure 10 shows early data taken on the induction furnace at National Steel over a 100minute period. The temperature fluctuated between 860 and $880^{\circ} \mathrm{F}$ over the time period. As indicated by the data, there was a process change at approximately 70 minutes into the run, which resulted in a slight decrease in the sheet temperature. At the step change, the sheet dimensions changed from 0.0490 inches thick and 39.19 inches wide to a thickness of 0.0645 inches and 44.13 inches wide. This is a good indicator of the sensitivity of the 
system. The measurements were made with an accuracy of $+/-9^{\circ} \mathrm{F}$ with a confidence level of $95 \%$.

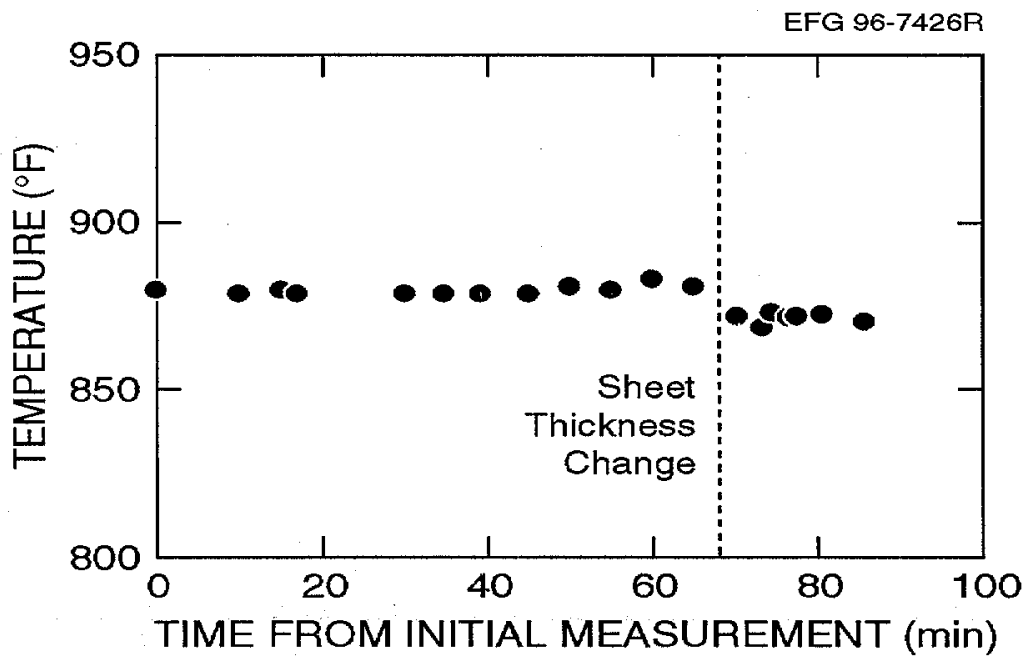

Figure 10-On-line phosphor thermometry

.In March of 1998 at Bethlehem Steel, phosphor thermometry data were taken and compared to a Type E hand-held contact thermocouple. Figure 11 shows a comparison between the phosphor thermometry data and the contact thermocouple data. The thermocouple data indicated a higher surface temperature, which is expected due to frictional heating of the thermocouple on the moving galvanneal sheet.

\section{Bethlehem Steel Test with Water Coating Only}

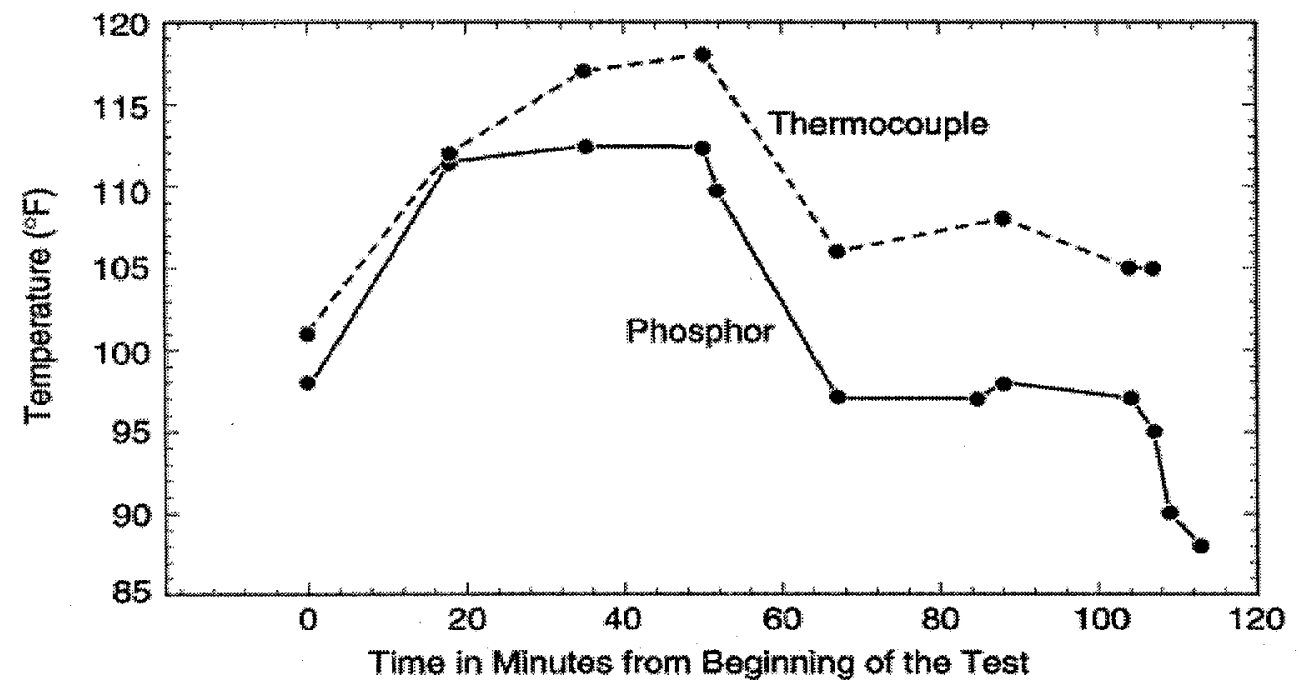

Figure 11 - Comparison of phosphor thermometry and a contact thermocouple

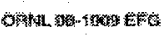


At the Bethlehem Steel Facility we adjusted the infrared furnace power levels and observed the temperature change on the galvanneal sheet (Figure 12). Note that for each step change in the furnace power level, there was a corresponding change in the surface temperature. The sensitivity of the phosphor thermometry system is demonstrated by the last several data points where the power level remained constant, while the sheet gauge thickness changed from 0.037 to 0.031 inches resulting in an increase in surface temperature of $4^{\circ} \mathrm{F}$.

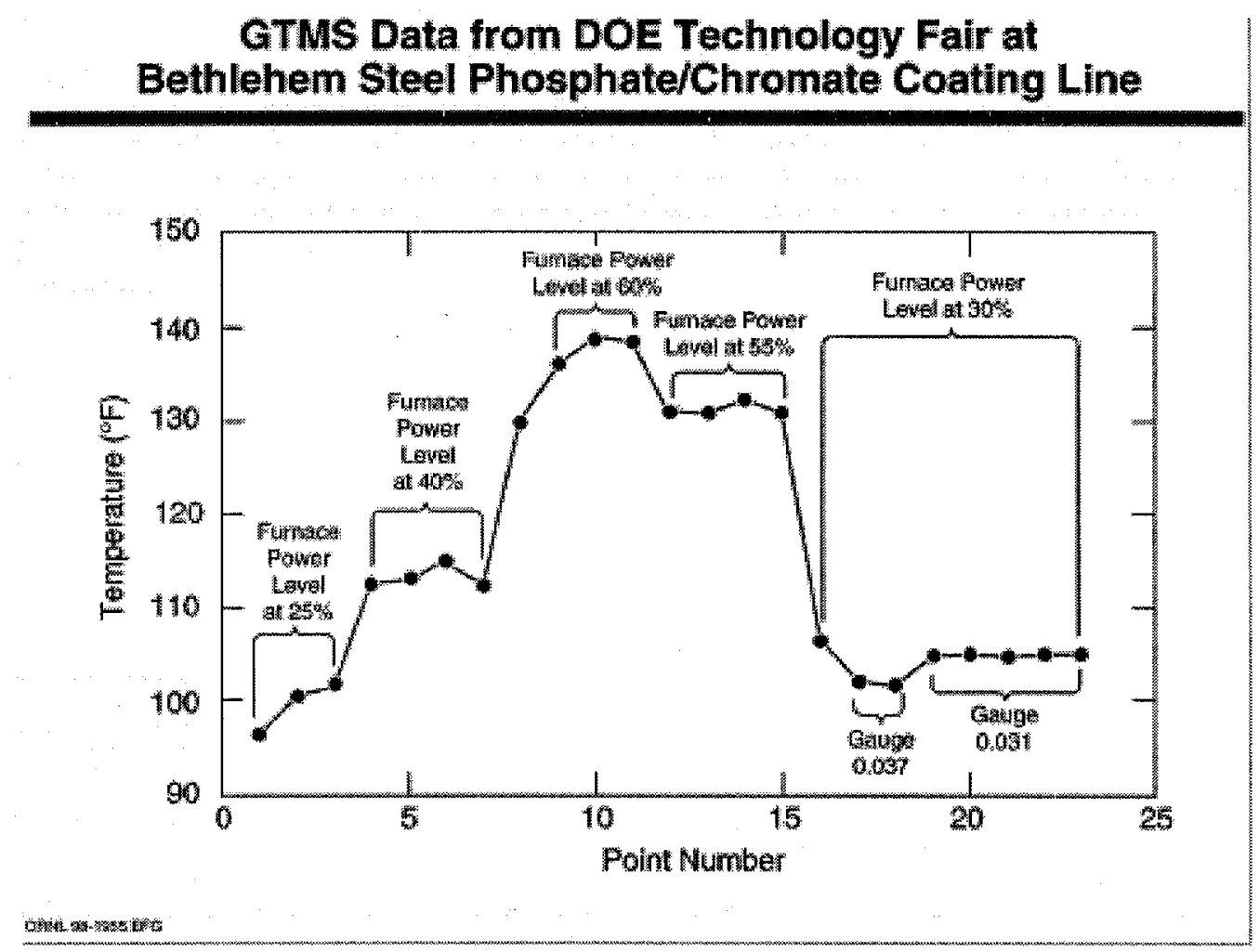

Figure 12 - Bethlehem Steel phosphate/chromate coating line data

\section{CONCLUSIONS}

We have described a new monitoring tool for quality control in the production of galvanneal steel. The GTMS provides crucial on-line thermal process control information during the manufacturing of galvanneal steel. The system has been used with the induction furnaces to measure temperatures ranging from $840-1292^{\circ} \mathrm{F}$ with an accuracy of better than $+/-9^{\circ} \mathrm{F}$. The GTMS was modified and installed on the galvanneal phosphate/chromate coating furnace area to measure temperatures ranging from room temperature to $248^{\circ} \mathrm{C}$ with an accuracy of better than $+/-5^{\circ} \mathrm{F}$. The GTMS provides accurate, reliable temperature information thus ensuring a high quality product, reducing waste, and saving energy. It provided for online temperature measurements of the sheet 
as it emerges from the zinc bath and is heated to form the galvanneal coating. It is a reliable means of tracking this critical production parameter. Additional work is being done to reduce the packaging size and to simplify the analysis electronics and software.

This technology is adaptable to other steel manufacturing applications. For such situations as slab heating, rolling mills, and melts, the conditions will be different and slight or extensive modifications to the existing approach may be necessary.

\section{REFERENCES}

ALLISON, S. W. AND GILLIES, G. T., 1997.

"Remote Thermometry with Thermographic Phosphors: Instrumentation and Applications," Rev. Sci. Instrum., v. 68, pp. 2615-2650.

ALLISON, S. W., GILLIES, G. T., CATES, M. R. AND NOEL, B. W., 1988.

Method for Monitoring Permanent Magnet Motor Heating with Thermographic Phosphors, IEEE J. of Inst. and Control, Vol. 37, No. 4, pp. 637-641.

CATES, M. R., ALLISON, S. W., MARSHALL, B. R., FRANKS, L. A., DAVIS, T. J., NELSON, M. A., AND B. W. NOEL, 1984.

Applications of Pulsed-Laser Techniques and Thermographic Phosphors to Dynamic Thermometry of Rotating Surfaces, Proc. of the Laser Inst. of Amer., Vol. 45, p. 4, Nov. 1985. (also Martin Marietta Energy Systems Report K/TS-11,504,).

GRATTAN, K. T. V. AND. ZHANG, Z. Y, 1995.

Fiber Optic Fluorescence Thermometry, Chapman and Hall.

NOEL, B. W., TURLEY, W. D. AND ALLISON, S. W. 1994.

"Thermographic Phosphor Temperature Measurements: Commercial and Defense-

Related Applications," Proc. 40th Int. Instrum. Symp., Instrum. Soc. of Am.,

Research Triangle Park, NC, pp. 271-288.

SUN, M., 1992.

"Fiberoptic Thermometry based on Photoluminescent Decay Times," in Temperature:

Its Measurement and Control in Science and Industry, edited by J. F. Schooley

(American Institute of Physics, New York), Vol. 6, Part 2, pp. 715-719.

WICKERSHEIM, K. A., 1992

"Fiberoptic Thermometry: An Overview," in Temperature: Its Measurement and Control in Science and Industry, edited by J. F. Schooley (American Institute of Physics, New York), Vol. 6, Part 2, pp. 711-714. 


\section{Distribution}

\section{Internal}

1. S. W. Allison

2. W. H. Andrews

3.-22. D. L. Beshears

23. M. R. Cates

24. R. M. Childs

25. E. C. Fox

26. E. B. Grann

27. M. A. Karnitz

28. W. W. Manges

29. T. J. McIntyre

30. S. R. McNeany

31. J. D. Muhs

32. M. B. Scudiere

33. M. L. Simpson

\section{External}

34. Rich Barcelona, Sr., Bailey Engineering, Inc., 125 Technology Drive, P. O. Box 401, Southpointe Industrial Park, Canonsburg, Pennsylvania, 15317

35.-44. Rich Barcelona, Jr., Bailey Engineering, Inc., 125 Technology Drive, P. O. Box 401, Southpointe Industrial Park, Canonsburg, Pennsylvania, 15317

45. William Dennis, 225 Linden Court, Sewickley, Pennsylvania, 15143

46. Tony Martocci, Bethlehem Steel Corp., $11708^{\text {th }}$ Ave, Room 449, Martin Tower, Bethlehem, PA 18016-7699

47. Charles Smith, Micro Controls Systems, Inc., 105 Southview Court, McMurray, Pennsylvania, 15317

48.-50. Joe Vehec, Advanced Process Control, The American Iron and Steel Institute, 247 Fort Pitt Boulevard, $2^{\text {nd }}$ Floor, Pittsburgh, Pennsylvania 15222 USA

51. John W. Wray, Bethlehem Steel Corp., Hot Dip Coating Division, P. O. Box 248, Chesterton, Indiana, 46304

52. Liwei Zhang, Technical Center, National Steel Corp, 1745 Fritz Drive, Trenton, Michigan 48183-2147 